\title{
International Practice
}

45 ADVANCE CARE PLANNING FOR GLBTI PEOPLE: RESULTS OF A STATE-WIDE SURVEY

10.1136/bmjspcare-2011-000053.45

C Cartwright Southern Cross University, NSW, Australia

Background Increasing evidence suggests that many gay, lesbian, bisexual, transgender and intersex (GLBTI) people are being denied their legal rights at the end-of-life. A 2009 study in Northern NSW (presented 2010 ACPEL Conference) found evidence of active discrimination and abuse of GLBTI people.

Methods A State-wide hard copy and on-line survey and indepth interviews were undertaken.

Results 305 useable questionnaires were returned; questionnaire distribution was via Newsletter \& websites so a response rate could not be determined.

The majority of respondents were open to all significant others; just over half were in a relationship; $77 \%$ had been in their relationship for 4 years or more.

Most respondents had high levels of education and income above that of the general population. Only $21 \%$ rated their health as Fair or Poor, while 53\% said it was excellent or very good.

Knowledge of/Experience with advance care planning (ACP) options was variable; most respondents did not understand the law relating to ACP. Few had discussed their end-of-life wishes with their doctor or significant others.

Those who were not out to significant others, had lower education and income and poorer health, are at greatest risk of inadequate care and not having their end of life wishes respected.

Conclusions As many GLBTI people are ageing, there is an urgent need for focussed education for GLBTI people about legally available ACP options and resources. Findings from this study and the pilot have resulted in a new GLBTI-specific ACP resource booklet.

Funding Study funded by Law and Justice Foundation of NSW. 